\title{
USGS National Water Quality Monitoring Network
}

\section{What is the U.S. Geological Survey National Water Quality Monitoring Network?}

Understanding the water quality of U.S. streams and rivers requires consistent data collection and analysis over decades. The U.S. Geological Survey's (USGS) National Water Quality Network (NWQN) was established to facilitate national-scale understanding of surface-water quality conditions through the collection of comparable data in large rivers and small streams in different geographic and land-use settings. Data collected by the NWQN support the needs of Federal, State, and local stakeholders tasked with managing our Nation's water resources.

\section{The NWON is designed to help answer the following questions:}

- What is the water quality of our Nation's streams and rivers?

- How are water-quality conditions changing over time?

The NWQN provides the data needed to understand how changing landscape and climatic conditions affect water quality. Data provided by the NWQN are the basis for assessments and models that characterize connections between landscape, climate, and water quality and that forecast potential changes in water quality.

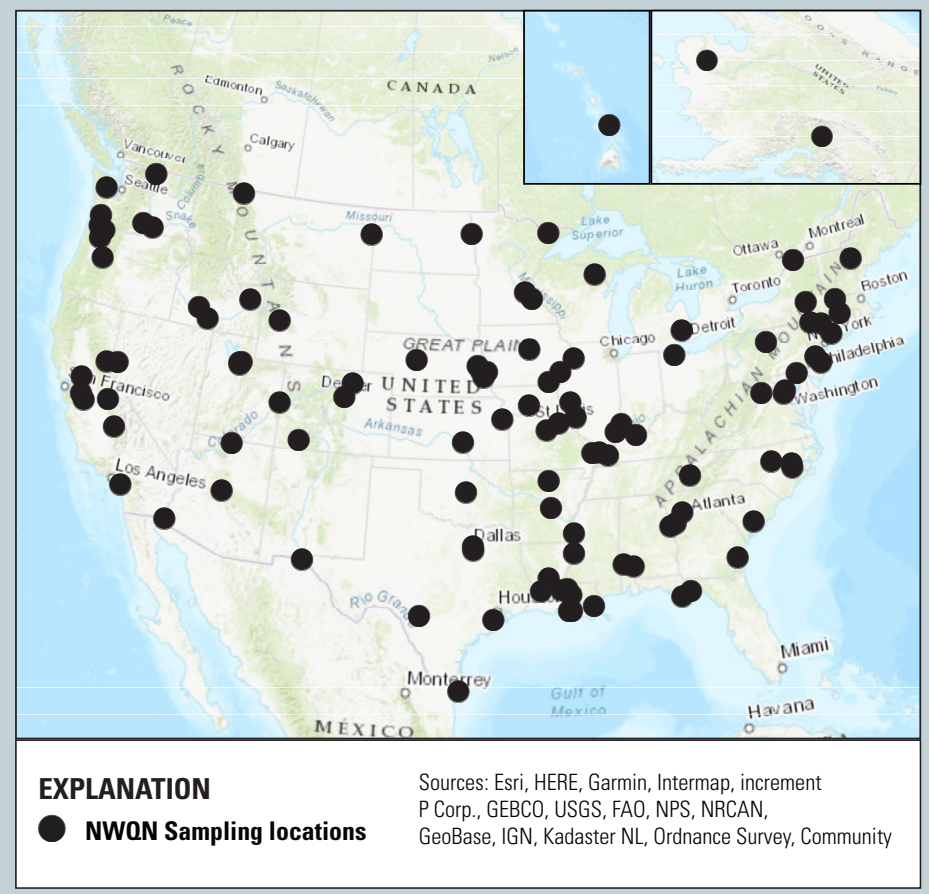

Figure 1. The 2021 National Water Quality Network study area and sampling sites.

\section{Building on Decades of Monitoring}

In 1962, the USGS Hydrologic Benchmark Network (HBN) was established to track changes in the flow and quality of water in streams and rivers in undisturbed watersheds. In the following decades, the number of national-scale water-quality monitoring networks expanded to include the National Stream Quality Accounting Network (NASQAN), the National Water-Quality Assessment Project (NAWQA), and the National Monitoring Network (NMN). In 2013, the USGS established the NWQN to ensure that consistent monitoring continued at selected sites from these historical networks. Sites prioritized for continued monitoring through the NWQN include sites upstream from key receiving waters (such as the Gulf of Mexico), sites with long-term historical records, and sites that improved network representation of different geographic and land-use settings. Additional information about these networks is available at https://nrtwq.usgs. gov/nwqn/\#/PREV.

\section{The National Water Quality Network in 2021}

The NWQN consists of 110 sampling sites located in large coastal and inland rivers, as well as small streams indicative of agricultural land use, urban land use, and reference (minimally disturbed) conditions (fig. 1). Streamflow and water-quality data are collected and analyzed using consistent methods to enable comparative assessments of water quality across the Nation and through time.

Sites monitored by the NWQN are typically sampled between 12 and 24 times per year, depending on site type. All samples are analyzed for physical properties, major ions, and selected trace elements and nutrients, while samples collected from coastal rivers, large-inland rivers, and agricultural and urban land-use sites are also analyzed for suspended-sediment and pesticide concentration. All NWQN sites are paired with streamgages operated by the USGS or other agencies that provide continuous (that is, hourly to daily) information on streamflow conditions. Selected sites also include continuous water-quality sensors, which provide hourly information on parameters like water temperature, $\mathrm{pH}$, specific conductance, turbidity, and dissolved nitrate concentration. 


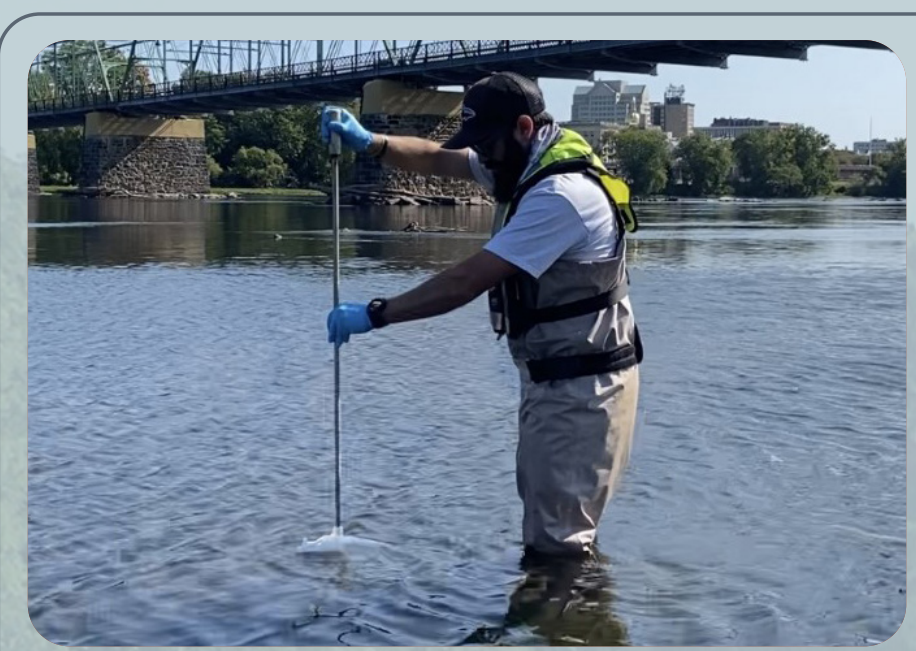

Figure 2. Sampling at the Delaware River at Trenton, N.J. (U.S. Geological Survey station 01463500). [Photograph by: Molly L. Schreiner]

\section{NWON Sampling, Laboratory, and Analysis Methods}

Where possible, water samples are collected using methods that take into account the width and depth of the stream cross section during sampling to facilitate data comparability across sites and through time (fig. 2). Samples are analyzed at the USGS National Water Quality Laboratory using documented methods. Quality-control samples, such as field blanks, field replicates, and field spikes, are analyzed annually at each site. Data for the NWQN are statistically analyzed using published methods and are updated annually on the Tracking Water Quality website and associated data releases.

\section{Tracking Water Quality in U.S. Streams and Rivers}

When paired with context on streamflow conditions, landscape characteristics, and other relevant data, analysis of NWQN results can provide important information on the mass of various water-quality constituents moving through rivers to receiving waters, how water-quality concentrations and loads are changing through time, and how pesticide concentrations compare to relevant human health and aquatic-life benchmarks. The USGS Tracking Water Quality webpage was created to provide these results to the public and to local, State, and Federal agencies tasked with managing our Nation's water resources. Along with observed water-quality concentrations and estimates of annual loads (see blue bars on fig. 3), the NWQN uses statistical methods to estimate trends in water-quality concentrations and loads outside of year-to-year variation in streamflow conditions. Blue lines on these graphs (fig. 3) illustrate the approximate trend in concentration or load through time. Results presented in the tables below the graphs quantify the magnitude of trend every decade before the most recent year of data collection. In addition, the Tracking Water Quality webpage provides information on the number of pesticides analyzed, detected, and how those detections relate to relevant human-health and aquatic-life benchmarks (fig. 4). These webpages are updated annually. Visit https://nrtwq.usgs. gov/nwqn for more information and to view site-specific data and graphs.

\section{By Melissa L. Riskin and Casey J. Lee}

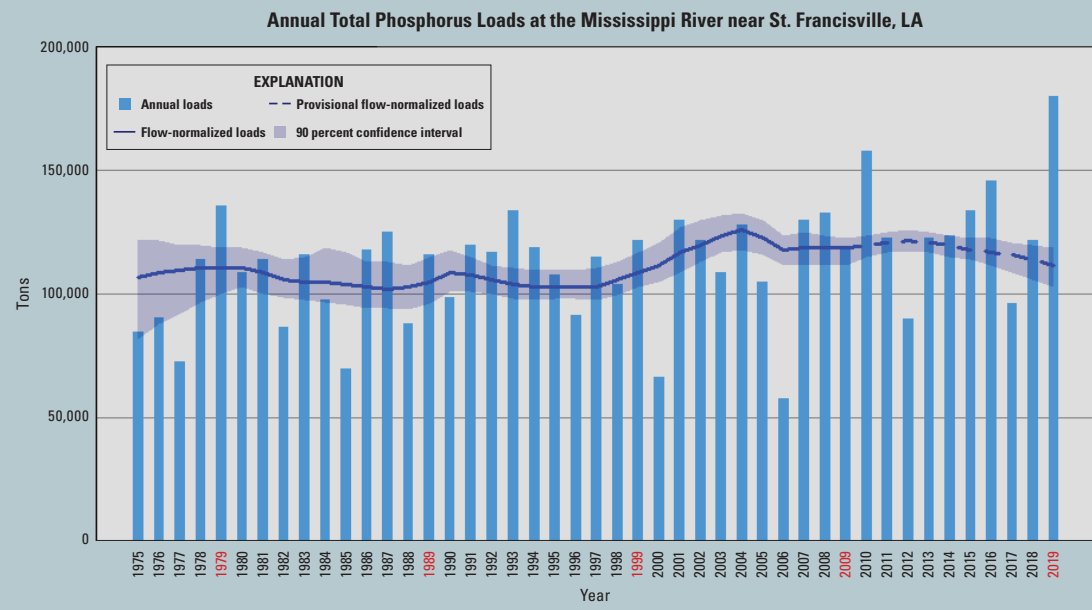

\begin{tabular}{lcccccc}
\hline $\begin{array}{c}\text { Trend start } \\
\text { year }\end{array}$ & $\begin{array}{c}\text { Trend end } \\
\text { year }\end{array}$ & $\begin{array}{c}\text { Trend, in percent } \\
\text { change (\%) }\end{array}$ & $\begin{array}{c}\text { Lower 90\% } \\
\text { confidence interval (\%) }\end{array}$ & $\begin{array}{c}\text { Upper 90\% } \\
\text { confidence interval (\%) }\end{array}$ & $\begin{array}{c}\text { Trend attributed } \\
\text { to changes in } \\
\text { streamflow (\%) }\end{array}$ & $\begin{array}{c}\text { Trend attributed to } \\
\text { other changes in the } \\
\text { watershed (\%) }\end{array}$ \\
\hline 1979 & 2019 & 0 & -16 & 16 & -1 & 1 \\
1989 & 2019 & 6 & -11 & 22 & 2 & 4 \\
1999 & 2019 & 2 & -12 & 18 & 0 & 2 \\
2009 & 2019 & -5 & -18 & 9 & 0 & -5 \\
\hline
\end{tabular}

Figure 3. Graph showing annual phosphorus loads and trends at the Mississippi River near St. Francisville, LA. (U.S. Geological Survey station 07373420).

\section{For More Information Contact:}

USGS National Water Quality Network Coordinator: Casey Lee

Email: cjlee@usgs.gov

Tracking Water Quality website: https://nrtwq.usgs.gov/nwqn

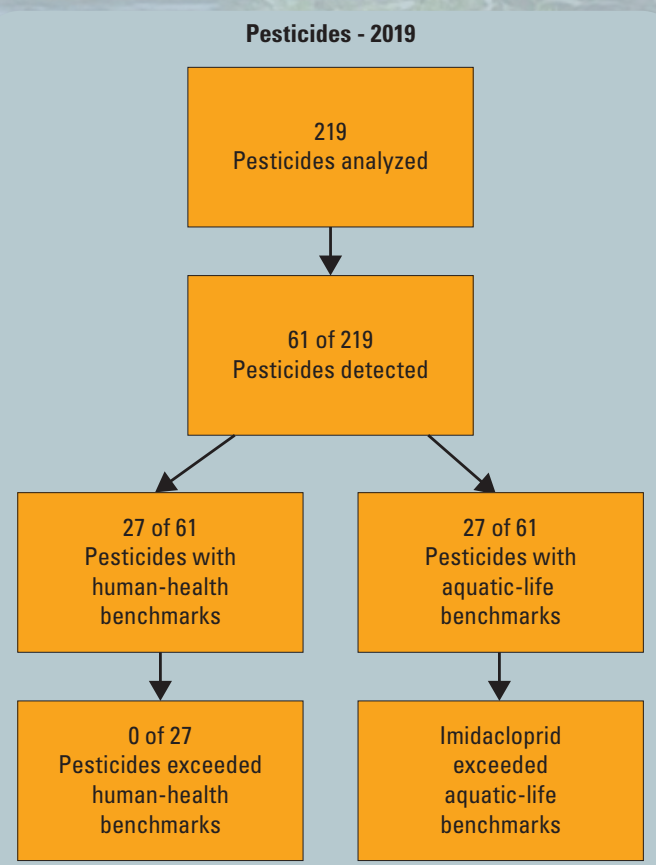

Figure 4. Summary of pesticide detections at Contentnea Creek at Hookerton, N.C., found at https://nrtwq.usgs.gov/nwqn/\#/. (U.S. Geological Survey station 02091500). 